\section{Modified fishing-line traction system in endoscopic submucosal dissection of large esophageal tumors}

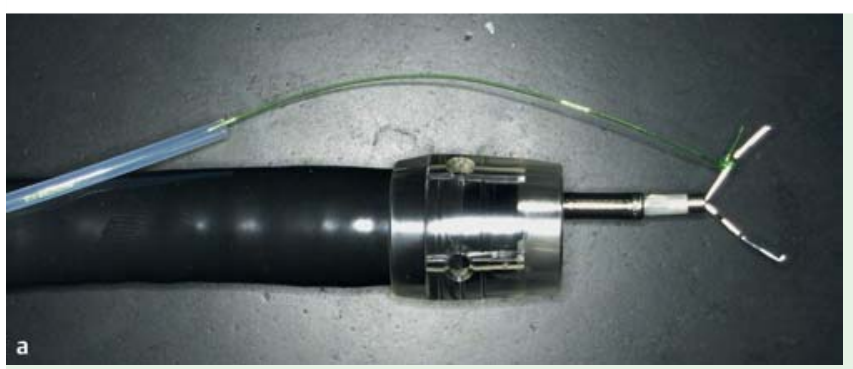

Fig. 1 a Fishing line tied to the endoclip. b A plastic sheath is inserted along the fishing line after placement of the endoclip.

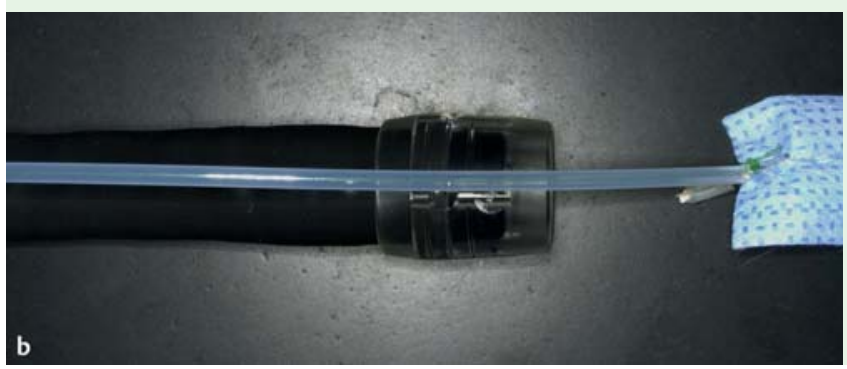

Endoscopic submucosal dissection (ESD) is a proven and safe technique in the en bloc removal of early gastrointestinal tract cancers [1]. With the array of available ESD devices and improvement in ESD techniques, it is now safe to resect lesions even in difficult locations, such as the esophagus [2]. However, technical challenges remain when attempting to resect large lesions in locations within a confined space. When the tumor occupies greater than threequarters of the esophageal circumference, the endoscopic view is diminished when the resection reaches the central portion of the tumor, making further resection difficult and unsafe. To counteract this problem, we have devised a modified version of a traction system previously described in the resection of intragastric lesions [3]. We advocate the use of an esophageal overtube to facilitate the withdrawal and reinsertion of the endoscope in such cases. Before introduction into the patient, an endoclip device is loaded into the endoscope and a length of $0.285-\mathrm{mm}$ fishing line is tied to one jaw of the endoclip ( Fig. $1 \mathbf{a}$ and $\mathbf{b}$ ).

The endoscope is reinserted into the patient through the overtube with the fishing line running alongside the shaft of the endoscope. The endoclip is placed over the central portion of the proximal margin of the partially resected tumor and a low resistance plastic sheath $(100 \mathrm{~cm})$ is inserted over the fishing line ( $\mathrm{Fig} . \mathbf{2} \mathbf{a}$ and $\mathbf{b}$ ).

\section{S. K. K. Tsao ${ }^{1}$, T. Toyonaga ${ }^{2}$, Y. Morita ${ }^{3}$,} T. Fujita ${ }^{3}$, T. Hayakumo ${ }^{3}$, T. Azuma ${ }^{3}$

1 Department of Gastroenterology, Tan Tock Seng Hospital, Singapore

2 Department of Endoscopy, Kobe University School of Medicine, Japan

3 Department of Gastroenterology, Kobe University School of Medicine, Japan

\section{References}

1 Inoue H, Minami H, Kaga M et al. Endoscopic mucosal resection and endoscopic submucosal dissection for esophageal dysplasia and carcinoma. Gastrointest Endosc Clin N Am 2010; 20: 25-34

2 Fujishiro M, Yahagi N, Kakushima $N$ et al. En bloc resection of a large semicircular esophageal cancer by endoscopic submucosal dissection. Surg Laparosc Endosc Percutan Tech 2006; 16: 237-241
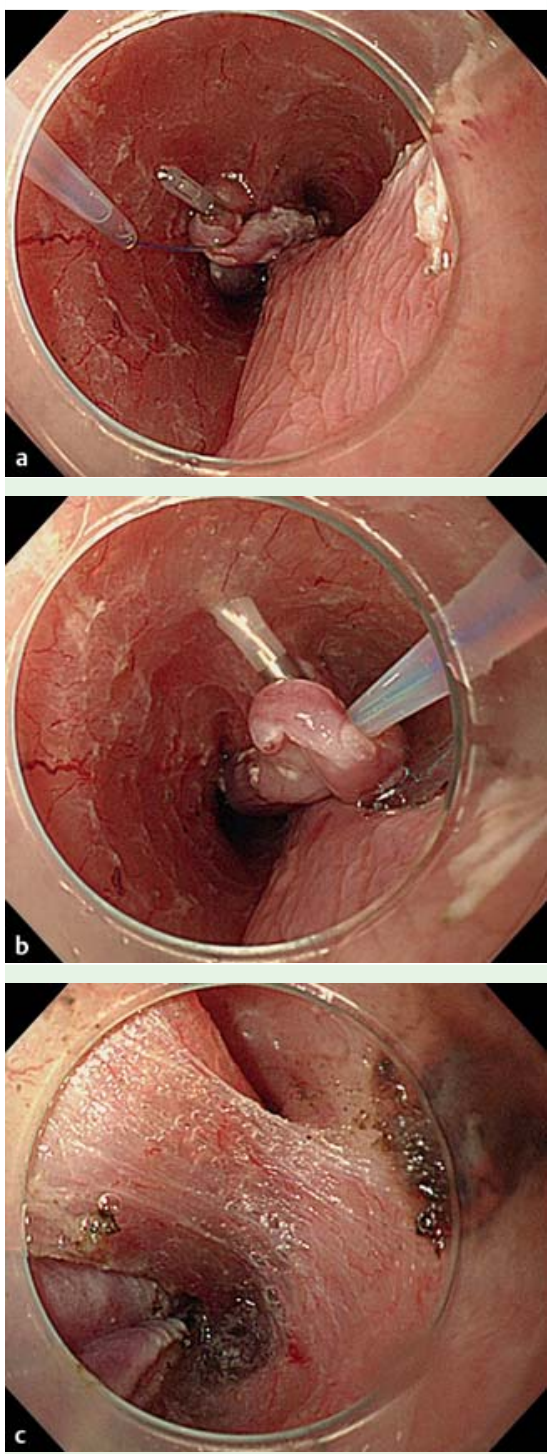

Fig. 2 a The endoclip with the fishing line attached is placed on the resected portion of the esophageal tumor. $\mathbf{b}$ The plastic sheath is inserted over the fishing line, as traction starts to be applied. c Full traction is applied, which leads to an improvement in endoscopic view and allows continuation of ESD.
3 Oyama T. ESD using intra-gastric lifting method. Endosc Dig 2002; 14: 11 [in Japanese]

Bibliography

Dol $10.1055 / \mathrm{s}-0030-1256144$

Endoscopy 2011; 43: E119

(c) Georg Thieme Verlag KG Stuttgart · New York ISSN 0013-726X

\author{
Corresponding author \\ T. Toyonaga, MD \\ Department of Endoscopy \\ Kobe University School of Medicine \\ 7-5-1 Kusunoki-cho, Chuo-ku \\ Kobe 650-0017 \\ Japan \\ toyonaga@med.kobe-u.ac.jp
}

